\title{
Low-temperature homoepitaxial growth on Si(111) mediated by thin overlayers of Au
}

\section{Citation}

Wilk, G. D., R. E. Martinez, John F. Chervinsky, Frans Spaepen, and J. A. Golovchenko. 1994. Low-Temperature Homoepitaxial Growth on Si(111) Mediated by Thin Overlayers of Au. Applied Physics Letters 65, no. 7: 866. doi:10.1063/1.112185.

\section{Published Version}

doi:10.1063/1.112185

\section{Permanent link}

http://nrs.harvard.edu/urn-3:HUL.InstRepos:29406271

\section{Terms of Use}

This article was downloaded from Harvard University's DASH repository, and is made available under the terms and conditions applicable to Other Posted Material, as set forth at http:// nrs.harvard.edu/urn-3:HUL.InstRepos:dash.current.terms-of-use\#LAA

\section{Share Your Story}

The Harvard community has made this article openly available.

Please share how this access benefits you. Submit a story.

\section{Accessibility}




\title{
Low-temperature homoepitaxial growth on Si(111) mediated by thin overlayers of $\mathrm{Au}$
}

\author{
G. D. Wilk, R. E. Martinez, John F. Chervinsky, Frans Spaepen, and J. A. Golovchenko \\ Division of Applied Sciences, Harvard University, Cambridge, Massachusetts 02138
}

(Received 11 May 1994; accepted for publication 3 June 1994)

High quality homoepitaxial growth of $\mathrm{Si}$ on $\mathrm{Si}(111)$ through an overlayer of $\mathrm{Au}$ is shown to occur at $450-500{ }^{\circ} \mathrm{C}$, far below the temperature required for growth of Si of similar quality on bare $\mathrm{Si}(111)$. Films of unlimited thickness can be obtained with excellent crystalline quality, as revealed by Rutherford backscattering spectrometry ion channeling measurements $\left(\chi_{\min }=2.2 \%\right)$. A distinct range of Au coverage (0.4-1.0 monolayer) results in the best quality epitaxy, with no measurable amount of $\mathrm{Au}$ trapped at either the interface or within the grown films. Cross-sectional transmission electron microscopy reveals that in films grown with Au coverages below and above the optimum range, the predominant defects are twins on (111) planes and Au inclusions, respectively.

Single crystal growth of semiconductors through surface mediating layers has been studied extensively in recent years. Wagner and Ellis first demonstrated metal-mediated crystal growth at $950^{\circ} \mathrm{C}$ through the vapor-liquid-solid (VLS) growth mechanism for semiconductors. ${ }^{1,2}$ VLS growth occurs through a thick, liquid eutectic layer, by transport of atoms from the vapor followed by their attachment to the solid substrate. In the first experiments, large-area planar growth could not be achieved because of insufficiently clean and homogencous surface conditions. With improved vacuum technology and hence surface cleanliness, growth of high quality, planar films became possible. ${ }^{3}$ Overlayer thicknesses have since been minimized so that transport through the mediating layer is not the limiting step in the growth mechanism. Several researchers have shown that mediating overlayers $^{4}$ can be used to improve homoepitaxial and heteroepitaxial growth of Si and Ge. ${ }^{5-9}$ These studies, however, have been limited to growth of very thin epitaxial layers [1-50 monolayers (ML), where $1 \mathrm{ML}=7.84 \times 10^{14} \mathrm{~cm}^{-2}$ on $\mathrm{Si}(111)]$, and this offers only a limited study of the microstructure. Iwanari et $a l^{5}$ have shown homoepitaxy of Si on Si(111) through a $\mathrm{Sn}$ layer at $330-420^{\circ} \mathrm{C} ; \cdot$ by observing growth of the first few monolayers with reflection highenergy electron diffraction and reflection electron microscopy. While these techniques are important for determining step flow and island nucleation on the Si surface during initial stages of growth, they cannot be used for analysis beyond the first few layers. It is desirable to be able to grow much thicker layers, so that the microstructure of the grown films can be studied on a larger scale.

Homoepitaxial growth on $\mathrm{Si}(111)$ is inherently difficult at low temperatures. Typically, the substrate must be held above $700{ }^{\circ} \mathrm{C}^{10}$ during deposition to obtain high quality films of unlimited thickness. Weir et al. ${ }^{11}$ have demonstrated homoepitaxial growth on bare $\mathrm{Si}(111)$ for limited thicknesses, at deposition rates of $0.1-3.0 \AA / \mathrm{s}$, and corresponding growth temperalures of $380-450^{\circ} \mathrm{C}$. The films were about $350 \AA$ thick, and the epitaxial quality deteriorated rapidly with distance from the initial interface. Buffer layers predeposited at $700^{\circ} \mathrm{C}$ were necessary to obtain clean substrate surfaces.

In this study we present a systematic investigation of $\mathrm{Au}$ coverages on the $\mathrm{Si}(111)$ surface which act as mediating lay- ers in the epitaxial growth of Si films. We show that there exists a narrow optimum range of Au coverages which produces grown films of excellent crystalline quality at low temperature, and leaves none of the surface Au trapped in the film. The films were grown without a predeposited buffer layer. We have grown epitaxial films up to $5000 \AA$ thick, and there are no indications of a limit to the thickness for films grown by our technique. Films grown over large planar areas in this manner, with surface overlayers of $\mathrm{Au}$, are important because of their potential use in device fabrication. We also discuss the effect of temperature on the crystalline quality of the epitaxial layers grown at various deposition rates, and analyze the resulting morphology of the films.

Samples were obtained from 3 in. $p$-type wafers, with $\rho=0.02-0.08 \Omega \mathrm{cm}$, and a miscut angle of $2.63^{\circ} \pm 0.15^{\circ}$. All samples were etched using the Shiraki procedure, ${ }^{12}$ then heated in situ at $900^{\circ} \mathrm{C}$ by direct current through the sample for 5 min under ultrahigh vacuum (UHV) conditions. The depositions werc done in an UHV chamber, with base pressure $7.0 \times 10^{-11}$ Torr. The substrate temperatures in this experiment ranged from 375 to $500{ }^{\circ} \mathrm{C}$, and were measured with an optical pyrometer. The pyrometer measurements agreed to $\pm 5^{\circ} \mathrm{C}$ with thermocouple calibration measurements over the temperature range used in this experiment. $\mathrm{Au}$ was deposited on atomically clean, $7 \times 7$ reconstructed substrate surfaces from a standard effusion cell; Si was then deposited by electron beam evaporation. In all cases the Au was deposited (at less than $0.1 \AA / \mathrm{s}$ ) at the same substrate temperature as the $\mathrm{Si}$. The deposition rates of $\mathrm{Si}$ were varied between 0.5 and $3.0 \AA / \mathrm{s}$, as determined by a quartz crystal monitor [calibrated by Rutherford backscattering spectrometry (RBS)]. Low-energy electron diffraction (LEED) was used to monitor the surface reconstruction after the Au deposition, as well as after the Si deposition. The samples were masked so that only half of the surface was covered by Au. In all samples Si was deposited over the entire surface, so that direct comparison could be made between regions with $\mathrm{Au}$ and regions without $\mathrm{Au}$ under otherwise identical conditions. Pressures during $\mathrm{Si}$ deposition were lower than $5.0 \times 10^{-9}$ Torr. After epitaxial growth, the samples were analyzed in situ by $\mathrm{RBS}\left(2 \mathrm{MeV}{ }^{4} \mathrm{He}^{+}\right)$and channeling. Some samples were analyzed ex situ in a separate beam line for 
glancing angle analysis. Oxidation during sample transfer caused no measureable change in the RBS spectra of the grown films. After RBS, most of the samples were studied by cross-sectional transmission electron microscopy (TEM).

Substrate temperature, Au coverage, and $\mathrm{Si}$ deposition rate were varied in this experiment in order to determine the effect of these parameters on the epitaxial quality of the film. Varying the Si deposition rate between 0.5 and $3.0 \AA / \mathrm{s} \mathrm{had}$ no observable effect on the quality of the films. This result is significant, since it differs from that for deposition on bare substrates, where the film quality depends strongly on deposition rate. ${ }^{11} \mathrm{Au}$ coverages ranged from 0.15 to $3.0 \mathrm{ML}$, and we found from LEED and RBS that the Au coverages and corresponding surface reconstructions before and after $\mathrm{Si}$ deposition at $375-500^{\circ} \mathrm{C}$ were the following: mixed $5 \times 1$ and $7 \times 7$ for $\mathrm{Au}$ less than $0.4 \mathrm{ML}$, mixed $5 \times 1$ and $\sqrt{3} \times \sqrt{3}$ for Au between 0.4 and $0.8 \mathrm{ML}$, only $\sqrt{3} \times \sqrt{3}$ (or $6 \times 6$, above 1 $\mathrm{ML}$ ) for $\mathrm{Au}$ above 0.8 ML. This is in agreement with previous observations, ${ }^{13}$ which used LEED and scanning tunneling microscopy. Before Si deposition, several samples were annealed at $750^{\circ} \mathrm{C}$ for $1 \mathrm{~min}$ immediately following $\mathrm{Au}$ deposition. The annealing caused no measurable change in the resulting epitaxial quality of the grown films.

Figure 1 shows four sets of RBS and channeling data under direct backscattering conditions for films grown at $450^{\circ} \mathrm{C}$. Figure 1 (a) shows spectra for growth of $1400 \AA \mathrm{Si}$ on bare $\mathrm{Si}(111)$. The high energy portion of the spectrum shows that no Au was deposited. The aligned spectrum has a relatively large $\chi_{\min }=30 \%$, which indicates that the film is highly defective. Figure 1(b) shows the spectrum for a 1700 $\AA$ film grown under the same conditions as (a), except that $0.15 \mathrm{ML}$ of Au was deposited prior to the Si deposition. This results in a drastic improvement in the aligned yield $\left(\chi_{\min }=10 \%\right)$. Figure 1(c) shows the random and aligned spectra of a $1000 \AA$ film grown with an Au coverage of 1.0 ML. It has the best quality of any of the films grown at
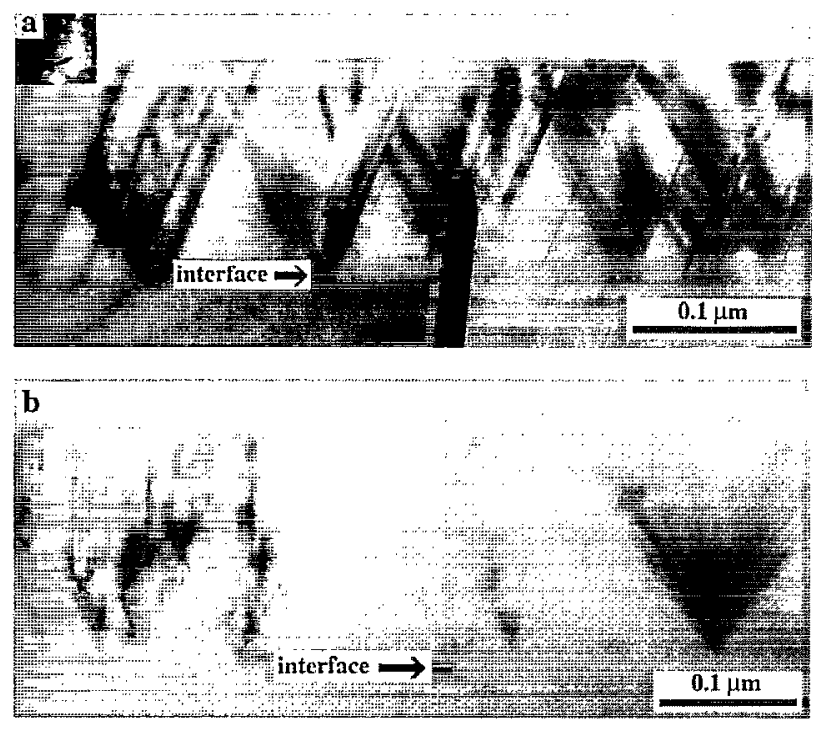

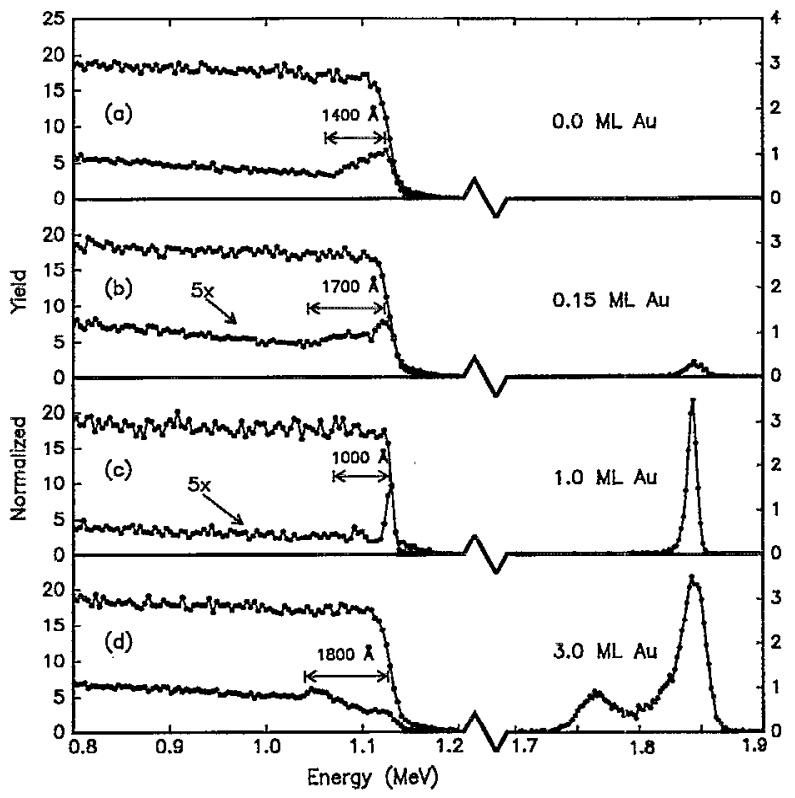

FIG. 1. RBS random and aligned spectra of Si grown on Si(111) through overlayers of different thickness; all substrates were at $450^{\circ} \mathrm{C}$. The normalized counts for the Au peaks at high energy are on the right axis. (a) $1400 \AA$ Si film grown with no (0.0 ML) Au. (b) $1700 \AA ̊$ Si film grown with $0.15 \mathrm{ML}$ of Au. (c) $1000 \AA \mathrm{Si}$ film grown with $1.0 \mathrm{ML}$ of Au; the aligned yields in both (b) and (c) have been multiplied by a factor of 5 in order to show detail in the spectra. (d) $1800 \AA$ Si film grown through $3.0 \mathrm{ML}$ Au with a large amount of Au trapped in the film.

$450^{\circ} \mathrm{C}$, as the aligned yield $\left(\chi_{\min }=2.4 \%\right)$ is nearly equal to that of a bare Si wafer. The channeling yields in Figs. 1(b) and 1(c) have been multiplied by a factor of 5 in order to show detail. Further, all of the Au remains at the surface of the film in both Figs. 1(b) and 1(c); no Au is detected at the substrate interface or in the grown film, as can be seen from the $\mathrm{Au}$ peak at high energy. Figure 1(d) shows the aligned
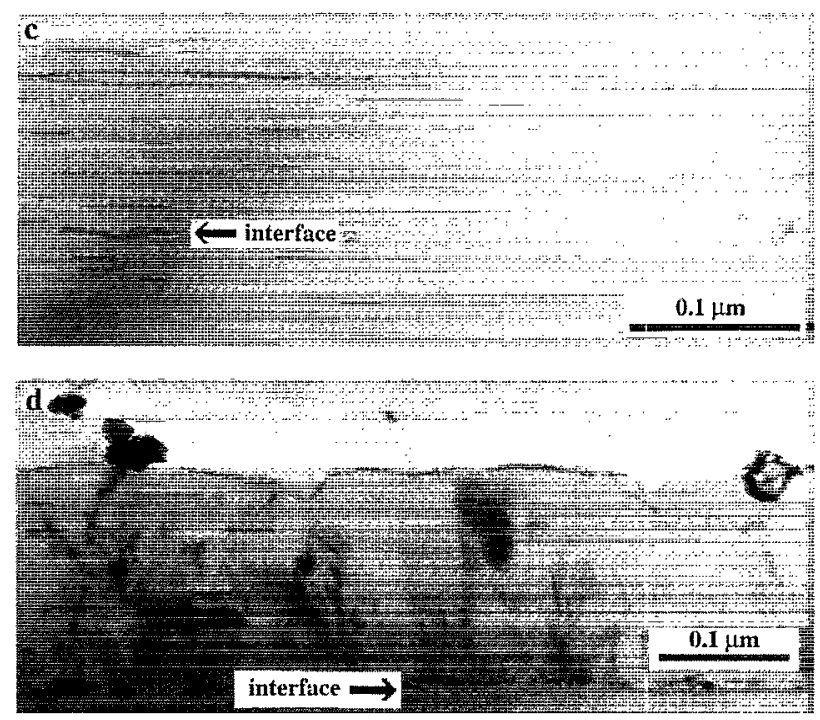

FIG. 2. Transmission electron micrographs of the samples in Fig. 1 (grown at $450^{\circ} \mathrm{C}$ ). (a) Highly defective film grown with no Au on the substrate surface, (b) slightly defective film [mostly twins on (111) planes] grown through $0.15 \mathrm{ML}$ Au, (c) nearly perfect crystal, showing no defects or Au trapped in film. (d) Large Au inclusions are on the film surface and trapped within the layer. 
spectrum for a $1800 \AA$ film grown with 3.0 ML Au. The epitaxial quality of the film is far worse than for $1.0 \mathrm{ML} \mathrm{Au}$, because about $1 \mathrm{ML}\left(7.7 \times 10^{14} \mathrm{~cm}^{-2}\right.$ measured) of Au was trapped at the interface and in the grown layer.

Figure 2 shows cross-sectional TEM micrographs of the corresponding samples in Fig. 1 , all grown at $450^{\circ} \mathrm{C}$. Figure 2(a) shows a Si film grown with no Au. The $1400 \AA$ film is highly defective, mostly from twins on (111) planes. The twins originate from the substrate interface, and extend to the film surface. The inset figure shows an electron diffraction pattern $(\langle 110\rangle$ beam direction) of the same region, with the streaks indicating twins on (111) planes. Two-dimensional nucleation at the initial interface appears to preclude good epitaxial growth from the onset. Figure 2(b) shows a $1700 \AA$ Si film grown with $0.15 \mathrm{ML}$ Au. While the film is much less defective than that of Fig. 2(a), the predominant defects are still twins on (111) planes. It appears that at coverages in this range, there is enough Au to facilitate high quality epitaxial growth in certain regions, but a substantial number of twins are still found in other regions. It should be noted, however, that substantial twinning does not begin at the initial interface: TEM shows that there is about $300 \AA$ of good epitaxial growth before significant twinning begins, and the aligned spectrum [Fig. 1(b)] showed no distinction between this layer and the substrate. Development of a nonuniform distribution of $\mathrm{Au}$ on the surface during growth may be the cause of the increased nucleation of twins.

Figure 2(c) shows a micrograph of a $1000 \AA$ Si epitaxial layer grown with $1.0 \mathrm{ML} \mathrm{Au}$. The grown layer is nearly defect free throughout the entire film thickness. The Au coverage is close to optimal and allows nearly perfect epitaxial growth, with no excess $\mathrm{Au}$ trapped in the film. For all $\mathrm{Au}$ coverages within the range $0.4-1.0 \mathrm{ML}$, the crystalline quality is excellent. The quality of films grown with $\mathrm{Au}$ coverages outside this range is much lower, as shown in Fig. 2(d), which shows a micrograph of a $1800 \AA \mathrm{Si}$ film grown at $450^{\circ} \mathrm{C}$ on $3.0 \mathrm{ML} \mathrm{Au}$. It can be seen that for coverages above about $1 \mathrm{ML}$, epitaxial growth still occurs, but that a large amount of $\mathrm{Au}$ is trapped both at the interface and in the grown layer.

Figure 3 is a plot of $\chi_{\min }$ as a function of Au coverage and temperature, at deposition rates of about $3 \AA / s$. The graph clearly shows that $\chi_{\min }$ is lowest for Au coverages between 0.4 and 1.0 ML. Above about 1.0 ML, a higher $\chi_{\min }$ results from dechanneling by $\mathrm{Au}$ trapped within the film. It can be seen that above $450{ }^{\circ} \mathrm{C}$ and with Au coverages in the optimum range, $\chi_{\min }$ is within a few percent of that for a bare Si wafer $\left(\chi_{\min }=2.2 \%\right)$. At $500^{\circ} \mathrm{C}, \chi_{\min }=2.2 \%$ for $\mathrm{Au}$ between 0.8 and $1.0 \mathrm{ML}$. The epitaxial quality of the films quickly deteriorates outside of this range, for reasons already discussed. Further, Fig. 3 shows that a temperatures as low as $410{ }^{\circ} \mathrm{C}$, epitaxial films $\left(\chi_{\min }=14 \%\right)$ can be grown with an $\mathrm{Au}$ coverage in the optimum range, even though $\mathrm{Si}$ grown with-

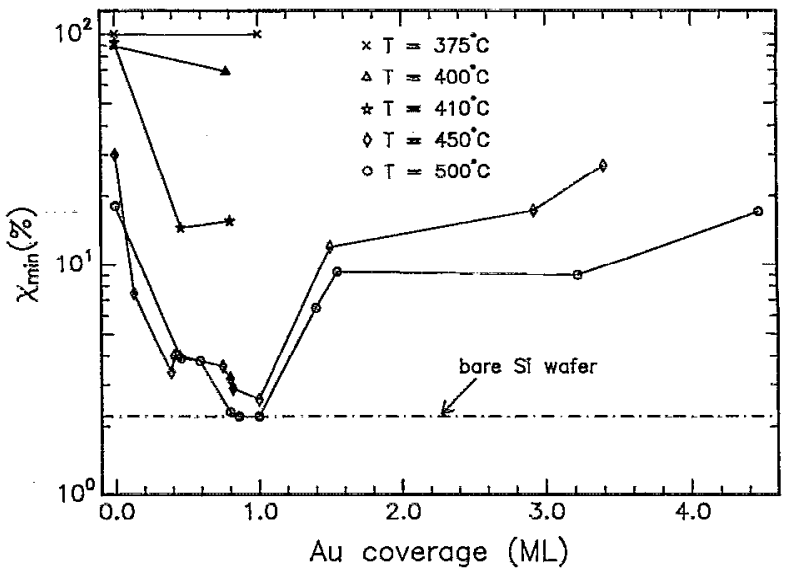

FIG. 3. Plot of $\chi_{\min }$ vs Au coverage at several temperatures, for a deposition rate of $3 \AA$ Às. At temperatures below $410^{\circ} \mathrm{C}$, Si films grown with or without $\mathrm{Au}$ are extremely defective. Above $450^{\circ} \mathrm{C}, \mathrm{Au}$ coverages betwecn 0.4 and 1.0 ML results in high quality epitaxial films.

out $\mathrm{Au}(0.0 \mathrm{ML})$ is extremely defective. At $375^{\circ} \mathrm{C}$, however, even films grown with $\mathrm{Au}$ are highly defective. The overall trend shows that the film quality improves with increasing temperature, and that defect-free films can be produced at temperatures as low as $450^{\circ} \mathrm{C}$; without $\mathrm{Au}$, similar quality can only be obtained above $700{ }^{\circ} \mathrm{C} .{ }^{10}$

We thank Y. Z. Lu for assistance with the electron microscopy. One of us (G.D.W.) acknowledges support from a Graduate Fellowship from the Office of Naval Research. This work has been supported by the National Science Foundation through the Harvard Materials Research Laboratory under Contract No. DMR-89-20490.

${ }^{1}$ R. S. Wagner and W. C. Ellis, Appl. Phys. Lett. 4, 89 (1964).

${ }^{2}$ R. S. Wagner and W. C. Ellis, Trans. Metall. Soc. AIMS 233, 1053 (1965).

${ }^{3}$ F. Xiong, E. Ganz, A. G. Loeser, J. A. Golovchenko, and F. Spaepen, Appl. Phys. Lett. 59, 3586 (1991).

"The term "surfactant" has gained some currency to describe a thin overlayer that mediates crystal growth. We prefer to reserve use of the term for situations where it is clearly demonstrated that the mechanism for crystal growth is governed by a decrease in the interfacial free energy. This certainly docs not apply in the casc of homocpitaxy.

${ }^{5}$ S. Iwanari and K. Takayanagi, Jpn. J. Appl. Phys. 30, L1978 (1991).

${ }^{6} \mathrm{~S}$. Iwanari and K. Takayanagi, J. Cryst. Growth 119, 229 (1992).

${ }^{7}$ M. Copel, M. C. Reuter, E. Kaxiras, and R. M. Tromp, Phys. Rev. Lett. 63, 632 (1989).

${ }^{8}$ M. Copel, M. C. Reuter, M. H. v. Hoegen, and R. M. Tromp, Phys. Rev. B 42, 11682 (1990).

${ }^{9}$ H. Nakahara and M. Ichikawa, Appl. Phys. Lett. 61, 1531 (1992).

${ }^{10} \mathrm{~F}$. Allen and E Kasper, Silicon-Molecular Beam Epitaxy, edited by E. Kasper and J. Bean (Chemical Rubber, Boca Raton, FL, 1988), Vol. 1.

${ }^{11}$ B. E. Weir, B. S. Freer, R. L. Headrick, D. J. Eaglesham, G. H. Gilmer, J. Bevk, and L. C. Feldman, Appl. Phys. Lett. 59, 204 (1991).

${ }^{12}$ A. Ishizaka, N. Nakagawa, and Y. Shiraki, in Proceedings of the 2nd International Symposium on Molecular Beam Epitaxy (Japanese Society of Physics, Tokyo, Japan, 1982), p. 182.

${ }^{13}$ A. A. Baski, J. Nogami, and C. F. Quate, Phys. Rev. B 41, 10247 (1990). 